Please do not remove this page

RMIT

UNIVERSITY

\title{
Interfacial resistive properties of nickel silicide thin films to doped silicon
}

Bhaskaran, Madhu; Sriram, Sharath; Holland, Anthony

https://researchrepository.rmit.edu.au/esploro/outputs/9921858181501341/filesAndLinks?institution=61RMIT_INST\&index=null

Bhaskaran, M., Sriram, S., \& Holland, A. (2010). Interfacial resistive properties of nickel silicide thin films to doped silicon. Journal of the Electrochemical Society, 157(8), 842-846. https://doi.org/10.1149/1.3454214 Document Version: Accepted Manuscript

Published Version: https://doi.org/10.1149/1.3454214

Repository homepage: https://researchrepository.rmit.edu.au

(C) The Electrochemical Society

Downloaded On 2023/04/27 00:35:11 +1000

Please do not remove this page 
Thank you for downloading this document from the RMIT Research Repository.

The RMIT Research Repository is an open access database showcasing the research outputs of RMIT University researchers.

RMIT Research Repository: http://researchbank.rmit.edu.au/

\section{Citation:}

Bhaskaran, M, Sriram, S and Holland, A 2010, 'Interfacial resistive properties of nickel silicide thin films to doped silicon', Journal of the Electrochemical Society, vol. 157, no. 8, pp. 842-846.

See this record in the RMIT Research Repository at:

http://researchbank.rmit.edu.au/view/rmit:4390

Version: Accepted Manuscript

Copyright Statement: (c) The Electrochemical Society

Link to Published Version:

http://dx.doi.org/10.1149/1.3454214 


\title{
Interfacial resistive properties of nickel silicide thin
}

\section{films to doped-silicon}

\author{
Sharath Sriram, ${ }^{*} \S$ Madhu Bhaskaran, ${ }^{\S}$ and Anthony S. Holland \\ Microelectronics and Materials Technology Centre and Platform Technologies \\ Research Institute, School of Electrical and Computer Engineering, RMIT University, \\ GPO Box 2476, Melbourne, Victoria 3001, Australia \\ *E-mail: sharath.sriram@gmail.com \\ $\S$ These authors contributed equally to this work.
}

\begin{abstract}
Improved means of electrical access to nanotechnology devices and accurate nanoscale characterization of electrical properties of ultra-thin layers constituting such electrical contacts is of utmost interest to nanoelectronics researchers. This article reports on the characterization of interfacial resistive properties of ohmic contacts to doped-silicon, incorporating thin films of nickel silicide. Silicon doping was achieved by carefully designed ion implantation of antimony (for n-type) and boron (for p-type). Cross Kelvin resistor test structures were used to extract the specific contact resistivity (SCR) values for the different ohmic contacts fabricated. SCR values, which are quantitative characteristics of interfacial resistive properties, as low as $5.0 \times 10^{-9} \Omega \mathrm{cm}^{2}$ for contacts to antimony-doped silicon and $3.5 \times 10^{-9} \Omega \mathrm{cm}^{2}$ to boron-doped silicon were estimated. These experimental results, representing the lowest such values measured, were based on a rigorous evaluation technique and verified by finite element modeling.
\end{abstract}

Keywords: contact resistance, specific contact resistivity (SCR), cross Kelvin resistor (CKR), nickel silicide, doped silicon, ion implantation 


\section{INTRODUCTION}

Electrical contacts to devices which pose low resistance continue to be of interest as the dimensions of devices decrease ${ }^{1}$ and nanotechnology demands better means of creating electrical access. ${ }^{2}$ In the semiconductor industry, nickel silicide (NiSi) is being used in current processes for local interconnects and in ohmic contacts. ${ }^{1}$ The desire to improve the performance of ohmic contacts creates the need for techniques to better characterize and quantify the performance of such contacts. Specific contact resistivity (SCR) is a quantitative measure of the resistance posed by an interface, and is denoted as $\rho_{\mathrm{c}}$ (in $\left.\Omega \mathrm{cm}^{2}\right)^{3}$

Multiple techniques have been utilised in measuring SCR values. Test structures based on transmission line model (TLM) are also commonly used to determine SCR. The limitations of the TLM in measuring low values of SCR (below $1 \times 10^{-7} \Omega \mathrm{cm}^{2}$ ) are discussed in Ref. 4. Cross Kelvin resistor (CKR) test structures were shown to be suitable for the measurement of low values of SCR, but the use of cumbersome error correction curves to estimate the value of SCR and inherent inaccuracies in the technique served as deterrents for the widespread use of this estimation technique. ${ }^{5-8}$

Recent publications demonstrate techniques for significant improvements in the measurement and extraction of low values of SCR, ${ }^{9-12}$ enabling the study of new material combinations. Although these recently reported approaches use 
both TLM and CKR test structures, ${ }^{9-12}$ they all aim to measure low values of SCR. Considering the use of nickel silicide in semiconductor (CMOS) technology to enable low contact resistance, accurate characterization of contacts incorporating nickel silicide with identification of doping parameters which tend to decrease SCR values is desirable. These approaches are readily transferable to nanotechnology contacts and their characterization. The motivation of these approaches is to accurately estimate the interfacial resistive properties of the interface in an area-independent manner. This will enable estimation of resistance of nanoscale contacts based on the fabrication and extrapolation of data from micron-scale contacts, without necessarily fabricating nanoscale contacts.

This article reports on the characterization of ohmic contacts comprising of aluminum to nickel silicide to doped silicon. Here, the aluminum-silicide SCR for the conductor-conductor combination will be very low, ${ }^{9}$ with the silicide-silicon SCR dominating the final result. The silicon was doped with antimony using two implant energy levels, in order to attain two different peak concentrations at the silicide-silicon interface. This article highlights the influence of the variation in dopant concentration on SCR values, and compares these results to SCR values measured for p-type boron implantation. SCR measurements were carried out using cross Kelvin resistor (CKR) test structures (Fig. 1) applying the technique described in Refs. 9 and 12, enabling the accurate extraction of low SCR values. These results are supported by finite element models corresponding to the experimental devices. 


\section{EXPERIMENTAL DETAILS}

\section{A. Ion implantation}

Silicon wafers were rinsed with acetone and isopropyl alcohol and dried using nitrogen. The chosen silicon wafers were of (100) orientation with resistivity of $1-10 \Omega \mathrm{cm}$. N-type wafers were used for boron implantation, while p-type wafers were used for antimony implantation. The wafers were subject to Piranha cleaning $\left(\mathrm{H}_{2} \mathrm{SO}_{4}: \mathrm{H}_{2} \mathrm{O}_{2}: \mathrm{H}_{2} \mathrm{O}:: 2: 1: 1\right.$ for $\left.15 \mathrm{~min}\right)$ and dipped in buffered hydrofluoric acid (BHF, for 30 seconds) to remove contamination and native oxide. Oxidation of the wafers was carried out at $1050{ }^{\circ} \mathrm{C}$. Dry oxidation was carried out for 10 minutes, followed by wet oxidation for 5 hours, which was followed by dry oxidation for 10 minutes. The oxygen flow rate was $1 \mathrm{~L} / \mathrm{min}$ throughout the process. The resulting oxide was approximately $1.2 \mu \mathrm{m}$ thick. The thermal $\mathrm{SiO}_{2}$ on the wafers was patterned (by a BHF etch) to create lower CKR 'L's of varying widths $(w)$ for ion implantation. The CKR arm widths used were 10,20 , and $30 \mu \mathrm{m}$. A thin oxide layer of $5-7 \mathrm{~nm}$ was grown thermally (dry oxidation, $1050{ }^{\circ} \mathrm{C}, 4$ minutes) to reduce channeling during ion implantation, due to availability of only substrate normal $\left(0^{\circ}\right)$ implantation.

Ion implantation was carried out using a metal vapor vacuum arc (MEVVA) ion source. Antimony (Sb) was used to create n-type regions, while boron (B) was used to define p-type regions. In the case of antimony, the peak concentration was designed to be on or around the NiSi-Si interface depth resulting from $15 \mathrm{~nm}$ of nickel used in the silicidation process. This depth was 
calculated to be $29 \mathrm{~nm} \cdot{ }^{13-15}$ In the case of boron doping, the same peak concentration depths could not be replicated as very low implant energies are required (and this was not within the ion implanter capabilities). The energy was chosen to provide a peak dopant concentration at a depth corresponding to the NiSi-Si interface depth (calculated to be $92 \mathrm{~nm}$ ) resulting from $50 \mathrm{~nm}$ of nickel. ${ }^{13-15}$ The ion implantation calculations were performed using the popular Stopping Range of lons in Matter (SRIM) package, 2006 version. ${ }^{16,17}$ The TRansport of lons in Matter (TRIM) calculation function in this package was used to determine appropriate implant energies for antimony and boron to achieve desired peak concentration depths. The results from TRIM calculations are illustrated in Fig. 2. From these results, the implantation conditions were determined, as summarized in Table I.

Based on these TRIM calculations (Table I), antimony implants at energies of $20 \mathrm{keV}$ and $40 \mathrm{keV}$ were carried out to create n-type regions in p-type silicon. Likewise, ion implantation of boron was carried out at $23.5 \mathrm{keV}$ to define p-type regions in n-type silicon. A fixed dose of $5 \times 10^{15}$ atoms $/ \mathrm{cm}^{2}$ was maintained for all implants. After ion implantation, dopant activation was performed by rapid thermal annealing (RTA) at $1000^{\circ} \mathrm{C}$ for 40 seconds in nitrogen ambient.

\section{B. Fabrication of cross Kelvin resistor test structures}

After ion implantation and post-implant anneal, the thermal oxide on the samples was stripped using buffered hydrofluoric acid. The samples were then prepared for lift-off using photolithography (to form circular contacts of different 
diameters $d$ ) following which $100 \mathrm{~nm}$ silicon dioxide $\left(\mathrm{SiO}_{2}\right)$ was evaporated using electron beam evaporation at room temperature. Lift-off was completed in an acetone bath. Samples were then coated with $15 \mathrm{~nm}$ nickel $(50 \mathrm{~nm}$ in the case of boron-implanted samples) using electron beam evaporation. The samples were then vacuum-annealed at $350{ }^{\circ} \mathrm{C}$ for $10 \mathrm{~min}(30 \mathrm{~min}$ for boronimplanted samples) to form nickel silicide (NiSi). Further details of the formation conditions of $\mathrm{NiSi}$ are described in Ref. 15. After this self-aligned silicidation step, the unreacted nickel was removed using a 2:1 solution of sulfuric acid and hydrogen peroxide. A $600 \mathrm{~nm}$ thick aluminum ( $\mathrm{Al}$ ) layer, deposited by electron beam evaporation, was patterned to form the upper arms of the CKR test structures. Mask patterns used to define CKR test structures and a plan view of one such fabricated test structure are shown in Fig. 3. The optical micrograph depicting the fabricated test structure [Fig. 2(b)] was obtained from a sample with antimony implanted at $40 \mathrm{keV}$, prior to annealing at $300^{\circ} \mathrm{C}$. The crosssection of the resulting contact region fabricated is depicted in the schematic in Fig. 4.

\section{Thermal treatment of cross Kelvin resistor test structures}

CKR test structures of varying contact sizes $(d)$ and different CKR arm widths $(w)$ were fabricated. The minimum value of diameters of the circular contacts was 0.8-1.0 $\mu \mathrm{m}$. The maximum contact diameters $(d)$ were chosen based on the CKR arm width $(w)$, such that $d / w$ values of up to $\sim 0.5$ were fabricated. For example, for $20 \mu \mathrm{m}$ are widths, contacts from 1-10 $\mu \mathrm{m}$ in steps of $\sim 0.5 \mu \mathrm{m}$ were fabricated. 
These $\mathrm{Al} / \mathrm{NiSi} / \mathrm{doped} \mathrm{Si}$ contacts were annealed, in an atmosphere of $3 \%$ hydrogen in nitrogen, at $300{ }^{\circ} \mathrm{C}$ in steps of $30 \mathrm{~min}$, to convert them from Schottky to ohmic contacts. SCR measurements of numerous CKR test structures were carried out using a micromanipulator probe station (The Micromanipulator Company) after each annealing step in order to study their variations with annealing time (up to $90 \mathrm{~min}$ ).

\section{RESULTS AND DISCUSSION}

\section{A. SCR measurements of Al/NiSi/Sb-doped Si}

Measured SCR values are influenced by parasitic resistance of the surrounding material, which are influence by the CKR geometry (contact diameter $d$ and CKR arm width $w$ ). As shown in our previous work, the measured SCR can be analyzed as a function of the ratio of $d / w^{9,12}$ Measurements were carried out for a number of devices with $d / w$ varying from $\sim 0.1$ to $\sim 0.5$ (for fixed values of $w$ ). Tables II and III list the highest and lowest measured SCR values $\left(\rho_{\mathrm{c}}{ }^{\prime}\right)$ for $\mathrm{Al} / \mathrm{NiSi} / \mathrm{Sb}$-doped Si contacts after different durations of annealing at $300{ }^{\circ} \mathrm{C}$. The tables show the maximum and minimum SCR values measured $\left(\rho_{\mathrm{c}}^{\prime}(\max )\right.$ and $\rho_{\mathrm{c}}^{\prime}(\min )$, respectively). As the numerical data reaches a minima $\left(\rho_{c}^{\prime}(\min )\right)$ as $d / w \rightarrow 0$ and a maxima $\left(\rho_{c}^{\prime}(\max )\right)$ near $d / w$ of $\sim 0.5$, these values are presented in the tables to provide an indication of the degree of parasitic resistance contributions. These measured values $\left(\rho_{\mathrm{c}}\right.$ ') include parasitic resistance contribution, and the true SCR value $\left(\rho_{\mathrm{c}}\right)$ is extracted from a 
collection of these values (illustratively described later and as shown in Refs. 9 and 12). The data in Tables II and III demonstrates the effect of annealing, with best measured SCR results obtained after $90 \mathrm{~min}$ of annealing. Further annealing does not impact SCR measurements. SIMS depth profiles were obtained for the entire stack of layers (Al/NiSi/Sb-doped $\mathrm{Si}$ ) to study the uniformity of layers, verify that aluminum spiking due to annealing had not occurred, and the positions and relative peak concentrations of the implant species with respect to the NiSi-Si interface. It was observed from the two SIMS depth profiles that the counts corresponding to the concentration of antimony in the samples implanted at $20 \mathrm{keV}$ is $\sim 100$ times higher relative to that for the samples implanted at $40 \mathrm{keV}$. Quantified concentrations could not be obtained due to the unavailability of relevant SIMS standards. The higher concentration in the lower energy implant is along expected lines (as shown in Table I) as the implant dose in both samples was the same, restricting the dopant to a tighter distribution.

Figure 5 illustrates SCR values measured for the samples implanted with antimony at $40 \mathrm{keV}$, after 90 min of annealing, for different CKR arm widths $w$ of 8,10 , and $20 \mu \mathrm{m}$. It is apparent that the measured values of SCR are higher as the CKR arm width increases. This is due to parasitic resistances contributed by the sheet resistance of the two 'L's - especially the doped silicon region - which increases as $w$ increases. ${ }^{12}$ The SCR values determined by extrapolation are between $0.7-1.5 \times 10^{-7} \Omega \mathrm{cm}^{2}$ for the different values of $w$, which is within acceptable levels of errors in SCR measurements. 
A comparison of measured SCR values (for $w$ of $20 \mu \mathrm{m}$ ) after 90 min of annealing for the samples with the two different antimony implant energies is shown in Fig. 6. This figure shows that the SCR of the samples with the higher dopant concentration is much lower. The SCR value for the samples implanted at $20 \mathrm{keV}$ is $5.0 \times 10^{-9} \Omega \mathrm{cm}^{2}$ as against $1.0 \times 10^{-7} \Omega \mathrm{cm}^{2}$ for the samples implanted at $40 \mathrm{keV}$. This significant decrease in SCR can be directly attributed to the $\sim 100$ times higher dopant concentration in the $20 \mathrm{keV}$ samples.

The evaluated SCR value of $5.0 \times 10^{-9} \Omega \mathrm{cm}^{2}$ is one of the lowest evaluated values reported for a doping concentration of $4.0 \times 10^{21}$ atoms $/ \mathrm{cm}^{3}$ for an $\mathrm{Al} / \mathrm{NiSi} / \mathrm{Sb}$-doped Si three-layer contact. The magnitude of this SCR value is comparable to $6.3 \times 10^{-9} \Omega \mathrm{cm}^{2}$ published in Ref. 10 for a doping concentration of $1.46 \times 10^{20}$ atoms $/ \mathrm{cm}^{3}$ for a NiSi/As-doped silicon contact.

\section{B. SCR measurements of $\mathrm{Al} / \mathrm{NiSi} / \mathrm{B}-$ doped $\mathrm{Si}$}

For comparative purposes, similar SCR measurements were also carried out for boron doped (p-type) silicon. Table IV lists the measured and evaluated values of SCR, with $90 \mathrm{~min}$ of annealing yielding an extrapolated $\rho_{\mathrm{c}}$ of $3.5 \times 10^{-9} \Omega \mathrm{cm}^{2}$. Figure 7 plots measured SCR values before annealing, after $30 \mathrm{~min}$, and after $90 \mathrm{~min}$ annealing. The SCR values were obtained for CKR line widths of $20 \mu \mathrm{m}$. There is a significant decrease in SCR values after the first 30 min of annealing, with further annealing causing small changes. The SCR values obtained after 60 and 90 min of annealing were very similar, with further 
annealing causing no difference. This evaluated value of $3.5 \times 10^{-9} \Omega \mathrm{cm}^{2}$ is the lowest reported value for a metal-silicide contact to p-type doped silicon.

Figure 8 presents the measured SCR values obtained for CKRs with arm width of $30 \mu \mathrm{m}$ (after 90 min of annealing). This enables comparison between the results for the 20 and $30 \mu \mathrm{m}$ CKR arm widths. These measured SCR values also extrapolate to a $\rho_{\mathrm{c}}$ of $3.5 \times 10^{-9} \Omega \mathrm{cm}^{2}$.

In order to bolster the experimental further, finite element modeling (FEM) was carried out with NASTRAN. Modeling was carried out for samples corresponding to those in Fig. 7 - nickel silicide to boron-doped silicon and CKR test structures with arm width of $20 \mu \mathrm{m}$. Three geometries were modeled for varying contact diameters $(d=1,2$, and $4 \mu \mathrm{m})$. The carrier concentration determined using SRIM in Table I and Ref. 18 were used to determine the resistivity of the doped region for these models. Assuming that the thickness of the doped region is the same as the ion range (considering a Gaussian distribution), the mean sheet resistance $\left(R_{\mathrm{SH}}\right)$ of the boron doped region was determined to be $43.47 \Omega / \mathrm{sq}$. Figure 9 (a) presents these FEM results and compares them with the experimental results presented previously in Fig. 7, for the curve related to the final result after annealing. Good agreement of these results is apparent, highlighting the veracity of the technique being applied to accurately determine such low values of SCR. The voltage and current distribution contours as shown by these models for the geometry corresponding to $d / w$ of 0.05 is shown in the other three panels of this figure [Fig. $9(b-d)]$. For 
further accuracy, these models require the definition of an ion implanted layer of varying resistivity with depth, directly related to the Gaussian profile of the implant as shown by TRIM in Fig. 2(c). Further refinements of these preliminary models related to ion implantation profiles is scope for future work.

\section{CONCLUSIONS}

Low values of specific contact resistivity for ohmic contacts incorporating nickel silicide have been evaluated. Measurements of SCR were carried out using CKR test structures for both antimony- and boron-doped samples. The influence of annealing on the SCR values is also reported. SCR values as low as $5.0 \times 10^{-9} \Omega \mathrm{cm}^{2}$ to antimony-doped (n-type) silicon and $3.5 \times 10^{-9} \Omega \mathrm{cm}^{2}$ to boron-doped (p-type) silicon were estimated. These values represent some of the lowest reported for a metal silicide to n-type silicon, while the value of $3.5 \times 10^{-9} \Omega \mathrm{cm}^{2}$ is the lowest value reported for a metal-silicide contact to $\mathrm{p}$-type doped silicon. Preliminary finite element modeling results for Al/NiSi/B-doped Si ohmic contacts are also discussed, showing good agreement with experimental outcomes. 


\section{ACKNOWLEDGEMENTS}

The authors acknowledge partial support for this project from the Australian Institute of Nuclear Science and Engineering and thank Dr. Peter J. Evans for his assistance.

\section{REFERENCES}

1. International Technology Roadmap for Semiconductors (ITRS), 2006 Update. (Available online at: http://www.itrs.net/links/2006Update/FinalToPost/09_Interconnect2006Update.pdf).

2. M. L. Roukes, Sci. Amer., 285, 48 (2001).

3. D. K. Schroder, Semiconductor Material and Device Characterization, 3rd ed., pp. 127-184, Wiley, Hoboken, NJ (2006).

4. M. Finetti, S. Guerri, P. Negrini, A. Scorzoni, and I. Suni, Thin Solid Films, 130, 37 (1985).

5. M. Finetti, A. Scorzoni, and G. Soncini, IEEE Electron Device Lett., EDL-5, 524 (1984).

6. W. M. Loh, S. E. Swirhun, T. A. Schreyer, R. M. Swanson, and K. C. Saraswat, IEEE Trans. Electron Devices, ED-34, 512 (1987).

7. A. Scorzoni and M. Finetti, IEEE Trans. Electron Devices, 35, 386 (1988).

8. A. S. Holland, G. K. Reeves, and P. W. Leech, IEEE Trans. Electron Devices, 51, 914 (2004).

9. M. Bhaskaran, S. Sriram, and A. S. Holland, IEEE Electron Device Lett., 29, 259 (2008). 
10. N. Stavitski, M. J. H. van Dal, A. Lauwers, C. Vrancken, A. Y. Kovalgin, and R. A. M. Wolters, IEEE Trans. Electron Devices, 55, 1170 (2008).

11. N. Stavitski, J. H. Klootwijk, H. W. van Zeijl, A. Y. Kovalgin, and R. A. M. Wolters, IEEE Trans. Semicond. Manuf., 22, 146 (2009).

12. A. S. Holland, G. K. Reeves, M. Bhaskaran, and S. Sriram, IEEE Trans. Electron Devices, 56, 2250 (2009).

13. L. A. Clevenger and R. W. Mann, in Properties of Metal Silicides, K. Maex and M. van Rossum, Editors, INSPEC, London (1995).

14. M. Bhaskaran, S. Sriram, D. R. G. Mitchell, K. T. Short, A. S. Holland, and A. Mitchell, Micron, 40, 11 (2009).

15. M. Bhaskaran, S. Sriram, A. S. Holland, and P. J. Evans, Micron, 40, 99 (2009).

16. J. P. Biersack and L. G. Haggmark, Nucl. Instr. Meth., 174, 257 (1980).

17. J. F. Ziegler, The Stopping and Range of lons in Matter, vol. 2-6, Pergamon Press, New York (1977-1985).

18. J. D. Plummer, M. D. Deal, and P. B. Griffin, Silicon VLSI Technology: Fundamentals, Practice and Modeling, p. 18, Prentice-Hall, New Jersey (2000). 


\section{TABLES WITH CAPTIONS}

Table I

Ion Implantation calculations showing the peak concentration depth. A constant dose of $5 \times 10^{15}$ atoms $/ \mathrm{cm}^{2}$ was used for all samples.

\begin{tabular}{cccc}
\hline $\begin{array}{c}\text { Implant } \\
\text { species }\end{array}$ & $\begin{array}{c}\text { Accelerating } \\
\text { voltage } \\
(\mathrm{keV})\end{array}$ & $\begin{array}{c}\text { Ion range } R_{\mathrm{P}} \\
(\mathrm{nm})\end{array}$ & $\begin{array}{c}\text { Ratio of } \\
\text { atoms } / \mathrm{cm}^{3} \text { to } \\
\text { atoms } / \mathrm{cm}^{2} \text { at } R_{\mathrm{P}}\end{array}$ \\
\hline $\mathrm{Sb}$ & 40.0 & 29.0 & $5.60 \times 10^{5}$ \\
$\mathrm{Sb}$ & 20.0 & 18.5 & $8.00 \times 10^{5}$ \\
$\mathrm{~B}$ & 23.5 & 92.0 & $1.50 \times 10^{5}$ \\
\hline
\end{tabular}


Table II

Measured and estimated values of specific contact resistivity for $\mathrm{Al} / \mathrm{NiSi} / \mathrm{Sb}$ doped Si (implantation energy of $20 \mathrm{keV}$ ) ohmic contacts annealed at $300^{\circ} \mathrm{C}$ for different annealing durations (CKR arm width of $20 \mu \mathrm{m})$.

\begin{tabular}{cccc}
\hline $\begin{array}{c}\text { Anneal time } \\
(\min )\end{array}$ & $\begin{array}{c}\rho \mathrm{c}^{\prime}(\max ) \\
\left(\Omega \mathrm{cm}^{2}\right)\end{array}$ & $\begin{array}{c}\rho \mathrm{c}^{\prime}(\min ) \\
\left(\Omega \mathrm{cm}^{2}\right)\end{array}$ & $\begin{array}{c}\rho \mathrm{c} \\
\left(\Omega \mathrm{cm}^{2}\right)\end{array}$ \\
\hline 0 & $1.1 \times 10^{-4}$ & $2.9 \times 10^{-7}$ & $1.0 \pm 0.5 \times 10^{-7}$ \\
30 & $3.0 \times 10^{-5}$ & $2.8 \times 10^{-8}$ & $1.0 \pm 0.5 \times 10^{-8}$ \\
60 & $5.4 \times 10^{-6}$ & $7.9 \times 10^{-9}$ & $5.0 \pm 1.0 \times 10^{-9}$ \\
90 & $5.4 \times 10^{-6}$ & $7.9 \times 10^{-9}$ & $5.0 \pm 1.0 \times 10^{-9}$ \\
\hline
\end{tabular}


Table III

Measured and estimated values of specific contact resistivity for $\mathrm{Al} / \mathrm{NiSi} / \mathrm{Sb}$ doped Si (implantation energy of $40 \mathrm{keV}$ ) ohmic contacts annealed at $300^{\circ} \mathrm{C}$ for different annealing durations (CKR arm width of $20 \mu \mathrm{m})$.

\begin{tabular}{cccc}
\hline $\begin{array}{c}\text { Anneal time } \\
(\min )\end{array}$ & $\begin{array}{c}\rho \mathrm{c}^{\prime}(\max ) \\
\left(\Omega \mathrm{cm}^{2}\right)\end{array}$ & $\begin{array}{c}\rho \mathrm{c}^{\prime}(\mathrm{min}) \\
\left(\Omega \mathrm{cm}^{2}\right)\end{array}$ & $\begin{array}{c}\rho \mathrm{c} \\
\left(\Omega \mathrm{cm}^{2}\right)\end{array}$ \\
\hline 0 & $1.4 \times 10^{-4}$ & $1.8 \times 10^{-6}$ & $9.0 \pm 1.0 \times 10^{-7}$ \\
30 & $3.6 \times 10^{-5}$ & $4.6 \times 10^{-7}$ & $3.0 \pm 0.5 \times 10^{-7}$ \\
60 & $3.3 \times 10^{-5}$ & $4.0 \times 10^{-7}$ & $1.0 \pm 0.5 \times 10^{-7}$ \\
90 & $3.3 \times 10^{-5}$ & $4.0 \times 10^{-7}$ & $1.0 \pm 0.5 \times 10^{-7}$ \\
\hline
\end{tabular}


Table IV

Measured and estimated values of specific contact resistivity for Al/NiSi/Bdoped Si (implantation energy of $23.5 \mathrm{keV}$ ) ohmic contacts annealed at $300^{\circ} \mathrm{C}$ for different annealing durations (CKR arm width of $20 \mu \mathrm{m}$ ).

\begin{tabular}{cccc}
\hline $\begin{array}{c}\text { Anneal time } \\
(\min )\end{array}$ & $\begin{array}{c}\rho \mathrm{c}^{\prime}(\max ) \\
\left(\Omega \mathrm{cm}^{2}\right)\end{array}$ & $\begin{array}{c}\rho \mathrm{c}^{\prime}(\mathrm{min}) \\
\left(\Omega \mathrm{cm}^{2}\right)\end{array}$ & $\begin{array}{c}\rho \mathrm{c} \\
\left(\Omega \mathrm{cm}^{2}\right)\end{array}$ \\
\hline 0 & $8.5 \times 10^{-5}$ & $2.1 \times 10^{-7}$ & $1.0 \pm 0.5 \times 10^{-7}$ \\
30 & $8.2 \times 10^{-6}$ & $2.9 \times 10^{-8}$ & $9.0 \pm 1.0 \times 10^{-9}$ \\
60 & $7.8 \times 10^{-6}$ & $1.2 \times 10^{-8}$ & $3.5 \pm 0.5 \times 10^{-9}$ \\
90 & $7.8 \times 10^{-6}$ & $1.0 \times 10^{-8}$ & $3.5 \pm 0.5 \times 10^{-9}$ \\
\hline
\end{tabular}




\section{FIGURE CAPTIONS}

Fig. 1. Schematic representation of a CKR test structure. Some notations used in this work are indicated.

Fig. 2. Ion range calculations generated using TRIM for implantation of antimony at $20 \mathrm{keV}$ in (a), antimony at $40 \mathrm{keV}$ in (b), and boron at $23.5 \mathrm{keV}$ in (c) are shown. All implantations were simulated for an angle of incidence of $0^{\circ}$ (substrate normal) related to the capabilities of the MEVVA instrument.

Fig. 3. An overlaid representation of the three-layer mask patterns used to create lower 'L' with $w$ of $20 \mu \mathrm{m}$, contact with $d$ of $4 \mu \mathrm{m}$, and upper 'L' with $w$ of $20 \mu \mathrm{m}$ of a CKR test structure is shown in (a). An optical micrograph of the fabricated $\mathrm{Al} / \mathrm{NiSi} / \mathrm{Sb}$-doped Si ohmic contact CKR test structure is shown in (b). The colored regions in (a) represent chromium with the scale bar corresponding to $10 \mu \mathrm{m}$.

Fig. 4. Cross-section schematic of the fabricated multi-layer contact CKR test structure. The aluminum and the ion implanted region form the two 'L's. The choice of thicknesses ensured that the $\mathrm{Al}-\mathrm{NiSi}$ interface lay below the $\mathrm{SiO}_{2}$ surface; thereby, ensuring the isolation between the two 'L's in the CKR test structure. (Not to scale) 
Fig. 5. Comparison of measured specific contact resistivity values after $90 \mathrm{~min}$ of annealing at $300{ }^{\circ} \mathrm{C}$ for CKR test structures with silicide arm widths of 8,10 , and $20 \mu \mathrm{m}$. These curves were obtained by annealing the sample with antimony implanted at $40 \mathrm{keV}$. The lines of least square fit for each set of data points are shown and the dotted lines are only to assist the reader in extrapolation of the data.

Fig. 6. Comparison of measured specific contact resistivity values after $90 \mathrm{~min}$ of annealing at $300{ }^{\circ} \mathrm{C}$ for CKR test structures with silicide arm width of $20 \mu \mathrm{m}$. These curves compare samples with antimony implanted at $20 \mathrm{keV}$ and $40 \mathrm{keV}$. The lines of least square fit for each set of data points are shown, with the dotted lines used only to assist the reader in extrapolation of the data.

Fig. 7. Comparison of measured specific contact resistivity values before and after various annealing steps at $300{ }^{\circ} \mathrm{C}$ for CKR test structures with boron implantation and silicide arm width of $20 \mu \mathrm{m}$. These values were obtained by annealing the boron-implanted samples. The lines of least square fit for each set of data points are shown, with the dotted lines used only to assist the reader in extrapolation of the data.

Fig. 8. Measured specific contact resistivity values $90 \mathrm{~min}$ of annealing at 300 ${ }^{\circ} \mathrm{C}$ for CKR test structures with boron implantation and silicide arm width of 30 $\mu \mathrm{m}$. 
Fig. 9. Comparison of measured specific contact resistivity values for CKR test structures with boron implantation and silicide arm width of $20 \mu \mathrm{m}$ with finite element modeling results in shown in (a). Voltage distribution in the threedimensional model of the doped silicon ' $L$ ' is shown in (b). The current density and voltage drops as current flows through the doped silicon ' $L$ ' and up the contact are shown in (c) and (d), respectively. All values shown on scale bars are in arbitrary units, with the modeling results in (b)-(d) corresponding to CKR with arm width $w$ of $20 \mu \mathrm{m}$ and contact diameter $d$ of $1 \mu \mathrm{m}(d / w=0.05)$. 


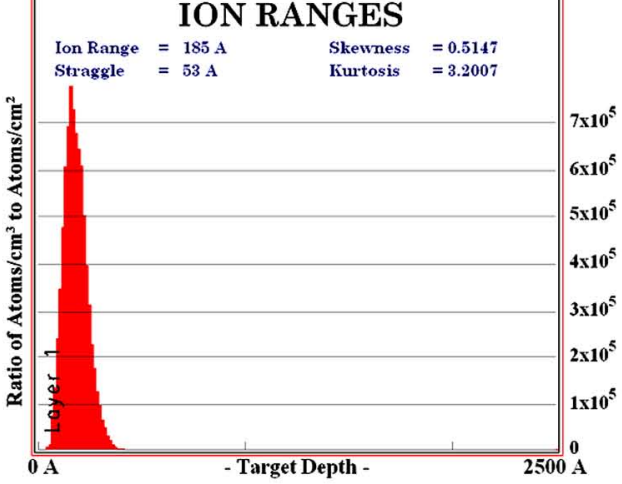

(a)

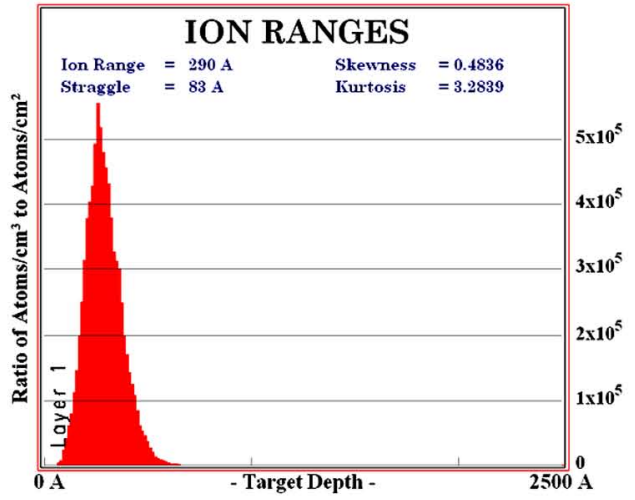

(b)

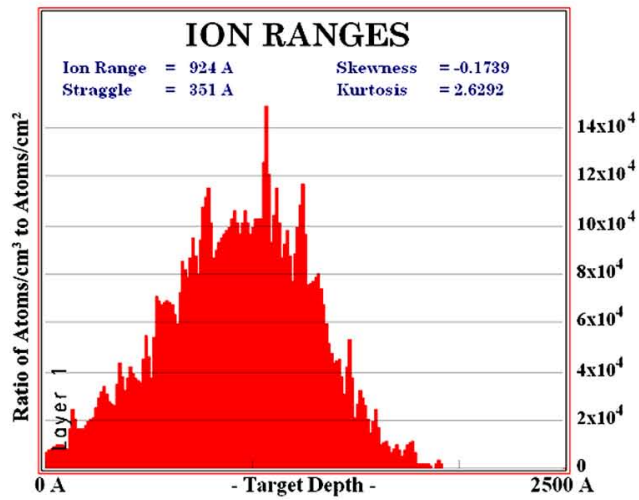

(c) 


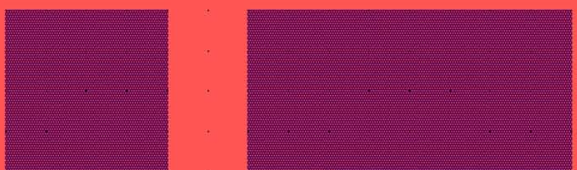

Diameter $d$

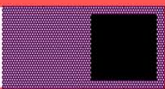

\section{Width $w$}

(a)
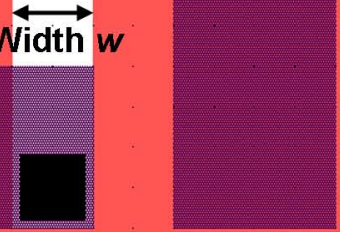

Width w

(b) 


\section{Aluminium}

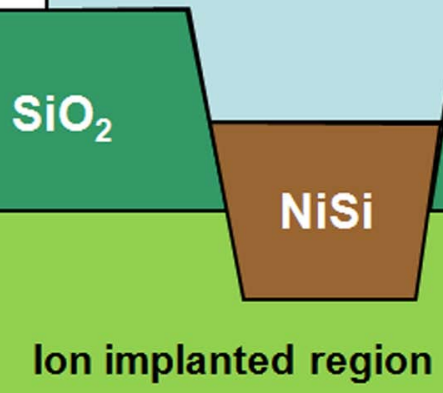

Silicon (100) 


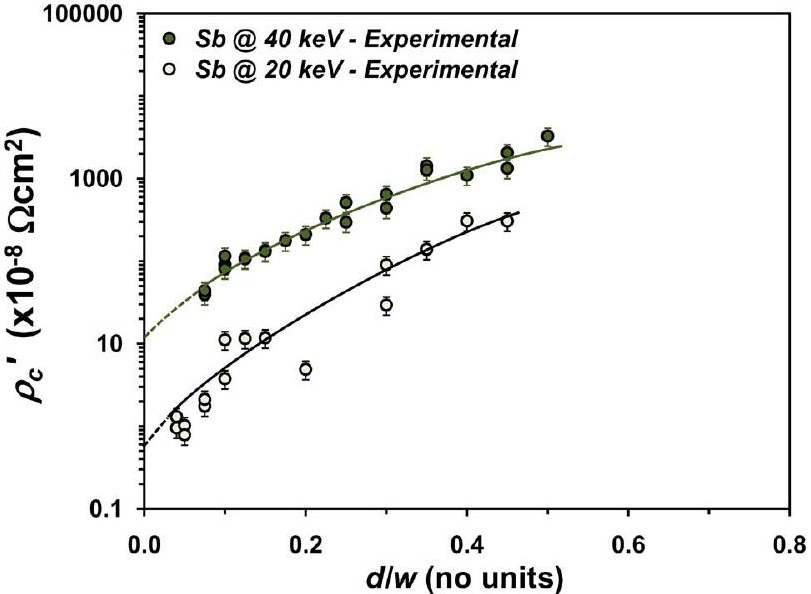




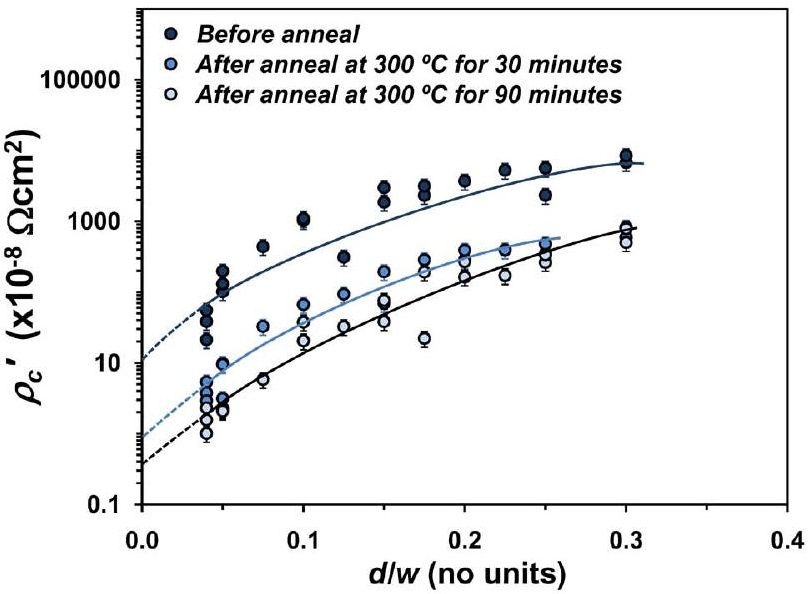




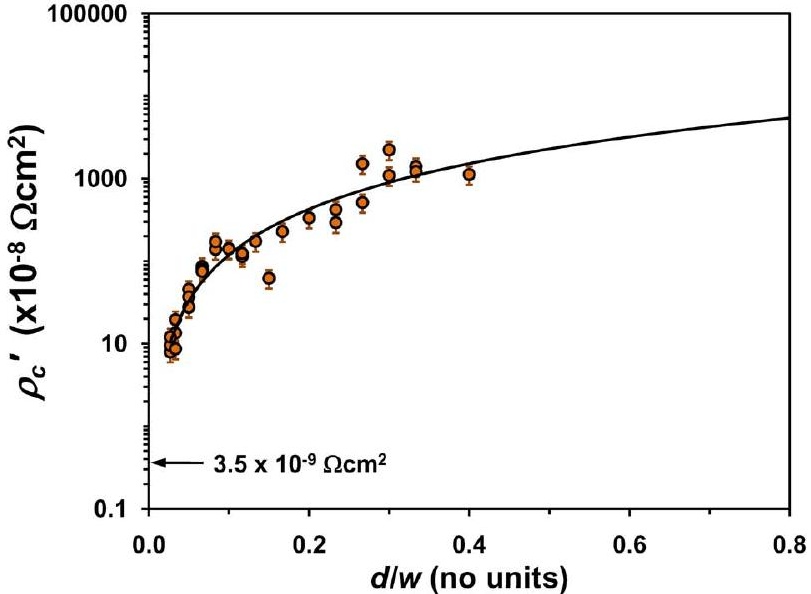




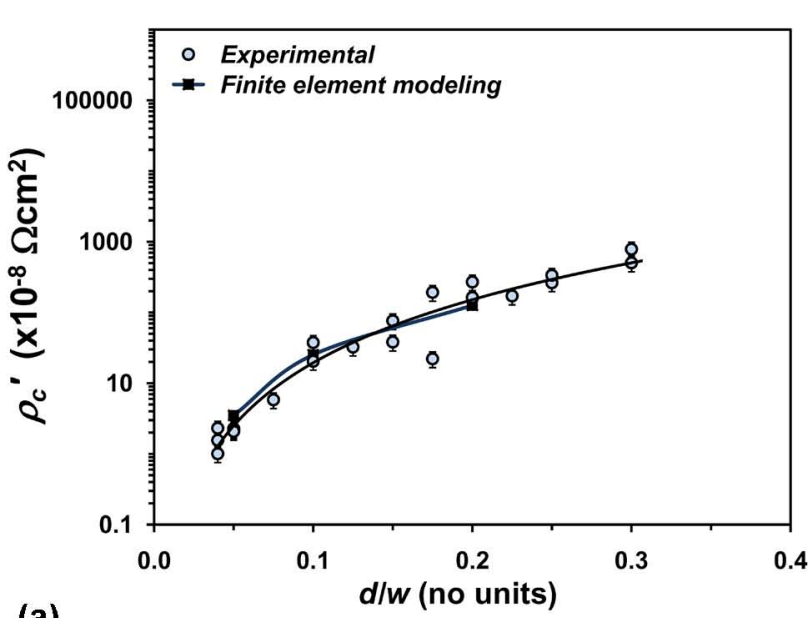

(a)

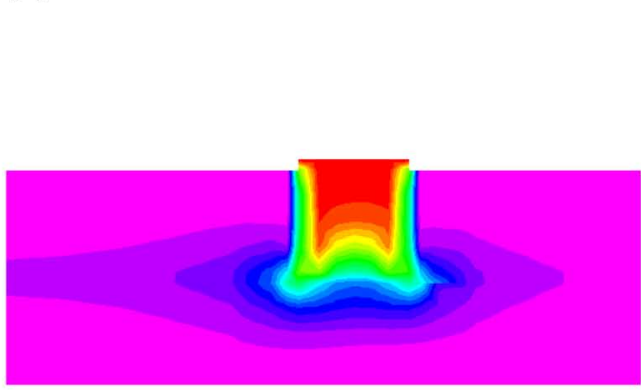

(c)

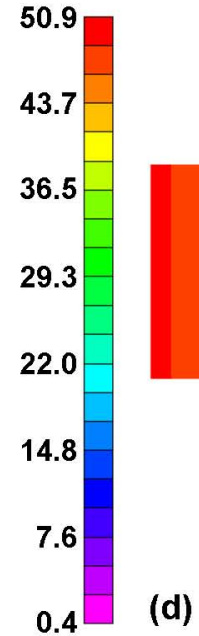

(b)

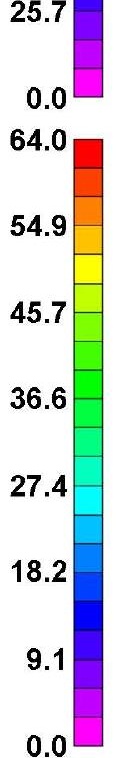

